\title{
Effect of Rivaroxaban and Clopidogrel Combination Therapy on In-Stent Responses After Everolimus-Eluting Stent Implantation in a Porcine Coronary Model
}

\author{
Daisuke Kitano ${ }^{1,2}$, Suguru Migita ${ }^{1}$, Yuxin $\mathrm{Li}^{2,3}$, Rie Takahashi ${ }^{4}$, Yoshiki Taniguchi ${ }^{4}$, Takafumi Kurosawa ${ }^{1}$, \\ Mitsumasa Sudo ${ }^{1,2}$, Hironori Haruta ${ }^{1}$, Takafumi Hiro ${ }^{1,2}$, Tadateru Takayama ${ }^{5}$, Masako Mitsumata ${ }^{6}$, \\ Taro Matsumoto $^{3}$, Yasuo Okumura ${ }^{1}$ and Atsushi Hirayama ${ }^{1,7}$ \\ Daisuke Kitano and Suguru Migita contributed equally to this work.
}

\begin{abstract}
${ }^{1}$ Division of Cardiology, Department of Medicine, Nihon University School of Medicine, Tokyo, Japan
${ }^{2}$ Division of Advanced Cardiovascular Imaging, Department of Medicine, Nihon University School of Medicine, Tokyo, Japan

${ }^{3}$ Division of Cell Regeneration and Transplantation, Department of Functional Morphology, Nihon University School of Medicine,

Tokyo, Japan

${ }^{4}$ Research Support Center, Research Institute of Medical Science, Nihon University School of Medicine, Tokyo, Japan

${ }^{5}$ Department of General Medicine, Nihon University School of Medicine, Tokyo, Japan

${ }^{6}$ Division of Pathology, Central Clinical Laboratory, Yamanashi Kosei Hospital, Yamanashi, Japan

${ }^{7}$ Cardiovascular Division, Osaka Police Hospital, Osaka, Japan
\end{abstract}

Aim: According to recent clinical trials, a combination of direct oral anticoagulants with antiplatelet drugs is often recommended for atrial fibrillation patients who receive drug-eluting stents (DESs). Although the optimal combination comprises direct factor Xa inhibitors and a $\mathrm{P} 2 \mathrm{Y}_{12}$ receptor antagonist (or aspirin), their influence on vascular responses to DESs remains unclear.

Methods: Pigs were given either aspirin and clopidogrel (dual antiplatelet therapy [DAPT] group), aspirin and rivaroxaban (AR group), or clopidogrel and rivaroxaban (CR group), followed by everolimus-eluting stent (Promus Element) implantation into the coronary artery. Stented coronary arteries were evaluated via intravascular optical coherence tomography (OCT) and histological analysis at 1 and 3 months.

Results: OCT revealed lower neointimal thickness in the DAPT group and comparable thickness among all groups at 1 and 3 months, respectively. Histological analyses revealed comparable neointimal area among all groups and the smallest neointimal area in the CR group at 1 and 3 months, respectively. In the DAPT and AR groups, the neointima continued to grow from 1 to 3 months. A shortened time course for neointima growth was observed in the CR group, with rapid growth within a month (maintained for 3 months). A higher incidence of in-stent thrombi was observed in the AR group at 1 month; no thrombi were found in either group at 3 months. More smooth muscle cells with contractile features were found in the CR group at both 1 and 3 months.

Conclusions: Our results proved the noninferiority of the combination of rivaroxaban with an antiplatelet drug, particularly the dual therapy using rivaroxaban and clopidogrel, compared to DAPT after DES implantation.

Key words: Atrial fibrillation, Rivaroxaban, Clopidogrel, Drug-eluting stent, Porcine model, Optical coherence tomography, Histology

\section{Introduction}

The widespread use of drug-eluting stents (DESs) represents a significant advancement in interventional cardiology, offering a solution to the long-standing problem of restenosis after coronary revascularization. Although improved DESs provide a reduction in in-stent restenosis and a reduced risk of stent thrombosis, prolonged antiplatelet therapy is still necessary to prevent these complications ${ }^{1,2)}$. Dual 
antiplatelet therapy (DAPT), such as the simultaneous administration of aspirin and $\mathrm{P}_{2} \mathrm{Y}_{12}$ receptor antagonists, is the mainstream treatment for patients with DESs. On the other hand, atrial fibrillation (AF) patients are administered both dual antiplatelet and oral anticoagulant (OAC) drugs when coronary stenting is required. However, triple therapy, including DAPT and warfarin, has been reported to dramatically increase bleeding events compared to DAPT ${ }^{3)}$.

Direct oral anticoagulants (DOACs) have only been developed within this decade. Recent clinical studies have, thus, revealed that the factor $\mathrm{Xa}(\mathrm{FXa})$ inhibitor rivaroxaban plus a $\mathrm{P} 2 \mathrm{Y}_{12}$ receptor antagonist reduce the risk of cardiovascular events in AF patients undergoing percutaneous coronary intervention with metallic stents when compared with a $\mathrm{P}_{2} \mathrm{Y}_{12}$ receptor antagonist only ${ }^{4}$ or DAPT plus dose-adjusted warfarin $^{5}$. Dual therapy, including a $\mathrm{P} \mathrm{Y}_{12}$ receptor antagonist and a direct oral thrombin inhibitor or FXa inhibitors, such as rivaroxaban or apixaban, can reduce bleeding events without increasing mortality when compared with triple therapy including DAPT and warfarin $^{6-8)}$. Considering the meta-analysis, dual therapy comprising $\mathrm{P} 2 \mathrm{Y}_{12}$ receptor antagonists and DOACs can be safe and effective for AF patients who receive $\mathrm{DESs}{ }^{9}$.

\section{Aim}

When considering bleeding risk, less antithrombotic therapy, such as a dual therapy comprising antiplatelets and DOACs may be preferred at the time of stenting; the duration of antithrombotic therapy should be shortened if the in-stent environments are stabilized during the early phase after DES implantation. However, in-stent tissue responses to the dual therapy comprising antiplatelets and DOACs early after DES implantation are not yet elucidated; moreover, the impact of dual therapy on the in-stent tissue responses compared to DAPT remains unclear. In this study, we examined whether the combination of rivaroxaban (a direct FXa inhibitor) with aspirin or clopidogrel (a P2Y12 receptor antagonist) was noninferior to DAPT regarding in-stent vascular responses after DES implantation in a porcine model, using an intracoronary imaging modality and histological assessment.

\section{Materials and Methods}

All animal care and experiments were performed following the Basic Guidelines for Conduct of Animal Experiments published by the Ministry of Health, Labor and Welfare, Japan, and were approved by the Institutional Committee for Use of Laboratory Animals of Nihon University School of Medicine (AP15M011).

\section{Animal Preparation}

Three-way cross pigs [Landrace, Large White, and Duroc (male, 3-4 months old, and weighing $35-40 \mathrm{~kg}$ )], supplied by the National Federation of Agricultural Cooperative Associations (ZEN-NOH, Tokyo, Japan), were orally administered one of the following antithrombotic therapy regimes (for 3 days before stent implantation and until the end of the study): aspirin $(81 \mathrm{mg} /$ day $)$ and clopidogrel $(75 \mathrm{mg} /$ day) (DAPT group, $n=10)$, aspirin ( $81 \mathrm{mg} /$ day) and rivaroxaban $(2 \mathrm{mg} / \mathrm{kg} / \mathrm{day})$ (AR group, $n=10)$, or clopidogrel $(75 \mathrm{mg} /$ day $)$ and rivaroxaban $(2 \mathrm{mg} / \mathrm{kg} /$ day) (CR group, $n=10$ ). The study protocol is shown in Fig. 1A. The dose of rivaroxaban was derived from both our preliminary experiments and previous data published by Becker et al. ${ }^{10)}$; the dose of $2 \mathrm{mg} / \mathrm{kg} / \mathrm{day}$ in pigs is equivalent to the anticoagulant activity of 15 $\mathrm{mg} /$ day in humans (data not shown).

After sedation with midazolam $(0.5 \mathrm{mg} / \mathrm{kg}, \mathrm{im})$, followed by inhaled sevoflurane $(5 \%)$ and heparinization $(5,000 \mathrm{U}$, ia) to inhibit blood clotting, we performed coronary angiography (CAG) and implanted an everolimus-eluting stent (Promus Element $^{\mathrm{TM}}$, Boston Scientific, Marlborough, MA, USA) in the left anterior descending coronary artery. Stents of $3.0 \times 16 \mathrm{~mm}$ were deployed with a 12 -atm inflation pressure to reach a 1.3:1 stent-to-artery ratio under the guidance of intravascular ultrasound (OptiCross catheter and iLab system, Boston Scientific). Follow-up CAG was performed at 1 (1-month observation subgroup, $n=5$ each) and 3 months (3-month observation subgroup, $n=5$ each) after implantation. After CAG, Optical coherence tomography (OCT) was performed to evaluate the in-stent neointimal formation; before stent deployment and at 1 and 3 months after stent deployment, blood was drawn for analysis.

Address for correspondence: Yuxin Li, Division of Cell Regeneration and Transplantation, Department of Functional Morphology, Nihon University School of Medicine, 30-1 Oyaguchi-kamicho, Itabashi-ku, Tokyo 173-8610, Japan E-mail: li.yuxin@nihon-u.ac.jp

Received: March 17, 2020 Accepted for publication: October 5, 2020

Copyright@2020 Japan Atherosclerosis Society

This article is distributed under the terms of the latest version of CC BY-NC-SA defined by the Creative Commons Attribution License. 
A

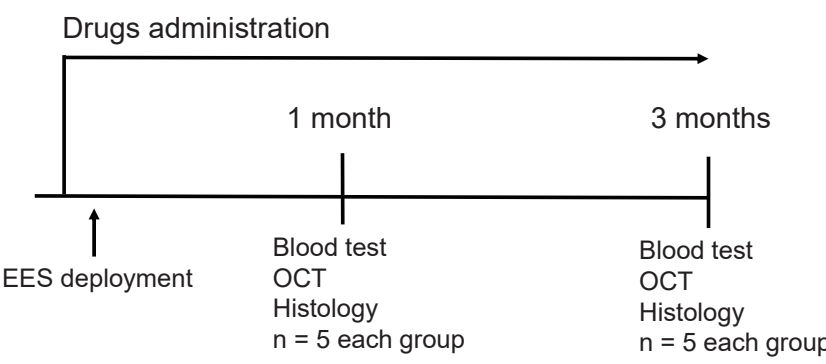

C

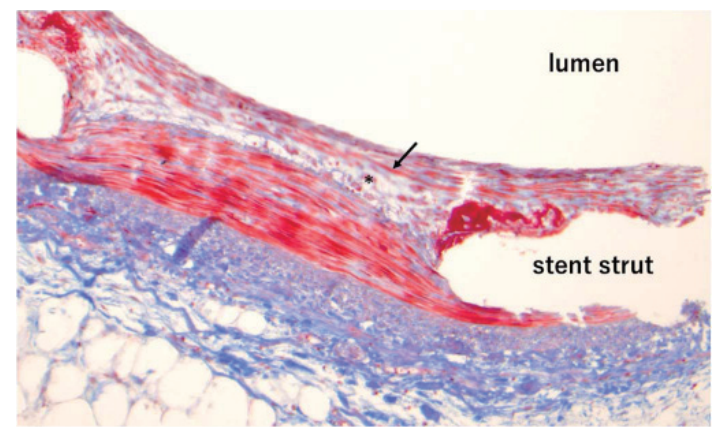

B

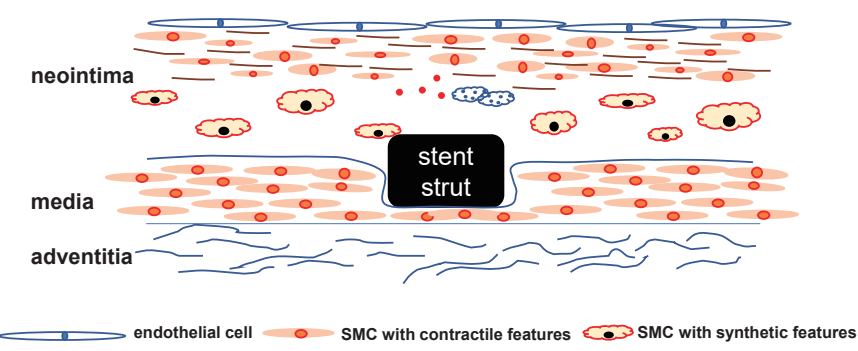

D

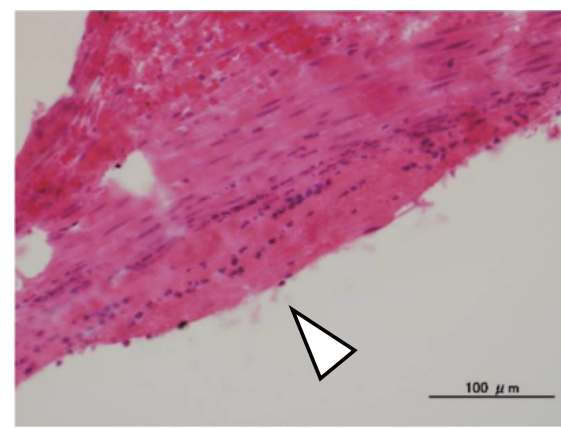

Fig. 1. Study design

(A) Schematic representation of the experimental timeline. (B) Illustration of the two subtypes of SMCs in the neointima surrounding a stent strut. (C) Representative case showing the location of the two subtypes of SMCs in a neointima stained with Masson's trichrome. SMCs with contractile features (arrow) are close to the lumen and layered on top of the neointima whereas those with synthetic features (asterisk) are scattered within the extracellular matrix below the layer of SMCs with contractile features, close to the media. (D) Representative case of in-stent thrombus. The white arrow indicates an in-stent thrombus comprising platelet and fibrin attached to the neointimal wall.

SMC, smooth muscle cell; EES, everolimus-eluting stent; OCT, optical coherence tomography

\section{OCT Analysis}

At 1 and 3 months after stent implantation, OCT analysis was performed; we used a frequencydomain OCT imaging system (C7 ILUMIEN OCT Intravascular Imaging Systems, St. Jude Medical, St. Paul, MN, USA) in this study. Using the frequencydomain OCT system, a 2.7-F OCT imaging catheter (Dragonfly, St. Jude Medical) was advanced distal to the stented lesion, while an automated pullback was initiated in concordance with blood clearance via the injection of contrast media. The automatic pullback rate was $20 \mathrm{~mm} / \mathrm{s}$, while the frame rate was 100 frames/s.

OCT images were assessed using software (OPTIS, Abbott Vascular, Santa Clara, CA, USA) as previously described ${ }^{11)}$. Cross-sectional OCT images were analyzed at $1-\mathrm{mm}$ intervals within the stented segment, $5 \mathrm{~mm}$ proximal and distal to the stent edges. Cross-sections with side branches or poor-quality OCT images were excluded from the analysis. As previously described ${ }^{12)}$, neointimal characteristics were classified into three pattern types (homogeneous, heterogeneous, and layered), and the proportions were computed. Lumen and stent areas were drawn in each analyzed cross-section; neointimal areas were calculated as [stent area-lumen area]. The neointimal thickness was only measured at each stent strut and was determined based on automated measurements performed from the center of the luminal surface of each strut blooming to the lumen contour ${ }^{13)}$.

\section{Histological Analysis}

At 1 and 3 months after stent implantation and after CAG and intracoronary imaging analysis, the pigs were sacrificed. The stented coronary arteries were harvested and perfused with saline and perfusionfixed with $10 \%$ buffered formalin to wash away circulating blood components. As previously described ${ }^{14,15)}$, the stented vessels were embedded in methyl methacrylate resin (FUJIFILM Wako Pure Chemical Industries, Osaka, Japan). Sections (4 $\mu \mathrm{m}$ each) were cut using a cemented tungsten carbide knife (RM2255, Leica, Germany) and stained with hematoxylin and eosin (HE) or Masson's trichrome (MT). Three sections each (proximal, mid, and distal) were acquired ${ }^{16)}$ with an optical microscope (CX41, 
Olympus, Tokyo, Japan) equipped with a DP27 camera (Olympus) and analyzed using the ImageJ software (ver. 1.52, National Institutes of Health, Bethesda, MD, USA) ${ }^{17)}$.

The histological evaluation included measurements of the vessel injury, neointimal area, and fibrin deposition area, the evaluation of neointimal characteristics and inflammation, and the assessment of the incidence of in-stent thrombi. Vessel injury caused by stent deployment was quantified using the vessel injury score as previously reported ${ }^{18,19)}$. In brief, at each stent strut, vessel wall damage was scored as Grade 0, internal elastic lamina was intact; Grade 1, internal elastic lamina lacerated and media compressed; Grade 2, internal elastic lamina and media lacerated and external elastic lamia compressed; and Grade 3, external elastic lamina was disrupted. As with OCT analysis, the neointimal thickness was only measured at the stent struts. Neointimal areas were measured around the stent and above the inner membrane ${ }^{20)}$, and a morphometric analysis of the smooth muscle cells (SMCs) was performed. Neointimal SMCs were divided into two subtypes: SMCs with contractile features and SMCs with synthetic features ${ }^{21-23)}$. Both subtypes were distinguished according to cell morphology, surrounding extracellular matrix (ECM), and their role in the formation of in-stent restenosis. Similar to cultured SMCs, SMCs with synthetic features in the neointima contain a high number of organelles involved in producing more ECM; however, these are largely replaced by contractile filaments in SMCs with contractile features. The rich contractile filaments comprising SMCs with contractile features are elongated and stain these cells more densely by $\mathrm{HE}$ or MT than SMCs with synthetic features. The decreased ECM production also promotes a tight alignment of SMCs with contractile features, while the less stretched SMCs with synthetic features are sparsely alienated between sufficient ECM (Fig.1B) ${ }^{24-26)}$. As shown in Fig.1B and 1C, SMCs with contractile features are located close to the lumen and layered on top of the neointima, whereas those with synthetic features are scattered within the ECM below the layer of SMCs with contractile features, close to the media. The area of the layer of SMCs with contractile features was measured; the relative area percentage of SMCs with contractile features was calculated as the area of SMCs with contractile features divided by the total neointimal area.

Defined by MT staining as a reddish area around the stent struts, the area of fibrin deposition was measured as previously described ${ }^{27)}$. Inflammation around the struts was semi-quantitatively graded via five high-power field observations around the struts per section. Inflammation scores were defined as Grade 0, few inflammatory cells except some foreign body giant cell infiltrations; Grade 1, mild, less than approximately 20 inflammatory cells; Grade 2, moderate, less than approximately 50 inflammatory cells; and Grade 3, severe, more than approximately 50 inflammatory cells per high-power field. In-stent thrombi were determined according to the existence of a heterogeneous composition, such as platelets and fibrin attached to the neointimal wall (arrow in Fig. 1D). Heparin was intravenously injected before sacrifice to inhibit blood clotting, and the stented coronary arteries were perfused with saline to wash away circulating blood. Images that were confused with an artifact or blood clots were not included in the measurement.

\section{Statistical Analysis}

Data were expressed as mean \pm standard error of the mean (SEM) and median [interquartile range] for normally and non-normally distributed variables, respectively. One-way analysis of variance or the Kruskal-Wallis test was performed as appropriate to compare differences across the three groups; post-hoc analyzes with the Steel-Dwass post-hoc analysis or Tukey's honestly significant difference test were performed to compare differences between groups. A chi-squared test was used to analyze the categorical variables between the three groups. All statistical analyzes were performed with RStudio (Version 1.1.463, RStudio, Inc., Boston, MA, USA), an integrated development environment for $\mathrm{R}$ (Version 3.5.2, The R Foundation for Statistical Computing, Vienna, Austria). A p-value of less than 0.05 was considered statistically significant.

\section{Results}

\section{Biochemical Analysis}

Laboratory data of the study animals are summarized in Table 1. There were no significant differences in initial blood samples among the three groups; in addition, parameters at 1 and 3 months after stent deployment did not differ among the three groups.

\section{OCT Findings}

As shown in Fig.2, Fig. 3A, and Table 2, compared with a heterogeneous or layered pattern, homogeneous patterns accounted for the majority in all groups at 1 month; in addition, compared with AR and CR groups, the DAPT group consisted of the highest proportions of homogeneous and 
Table 1. Laboratory data of study animals per treatment group

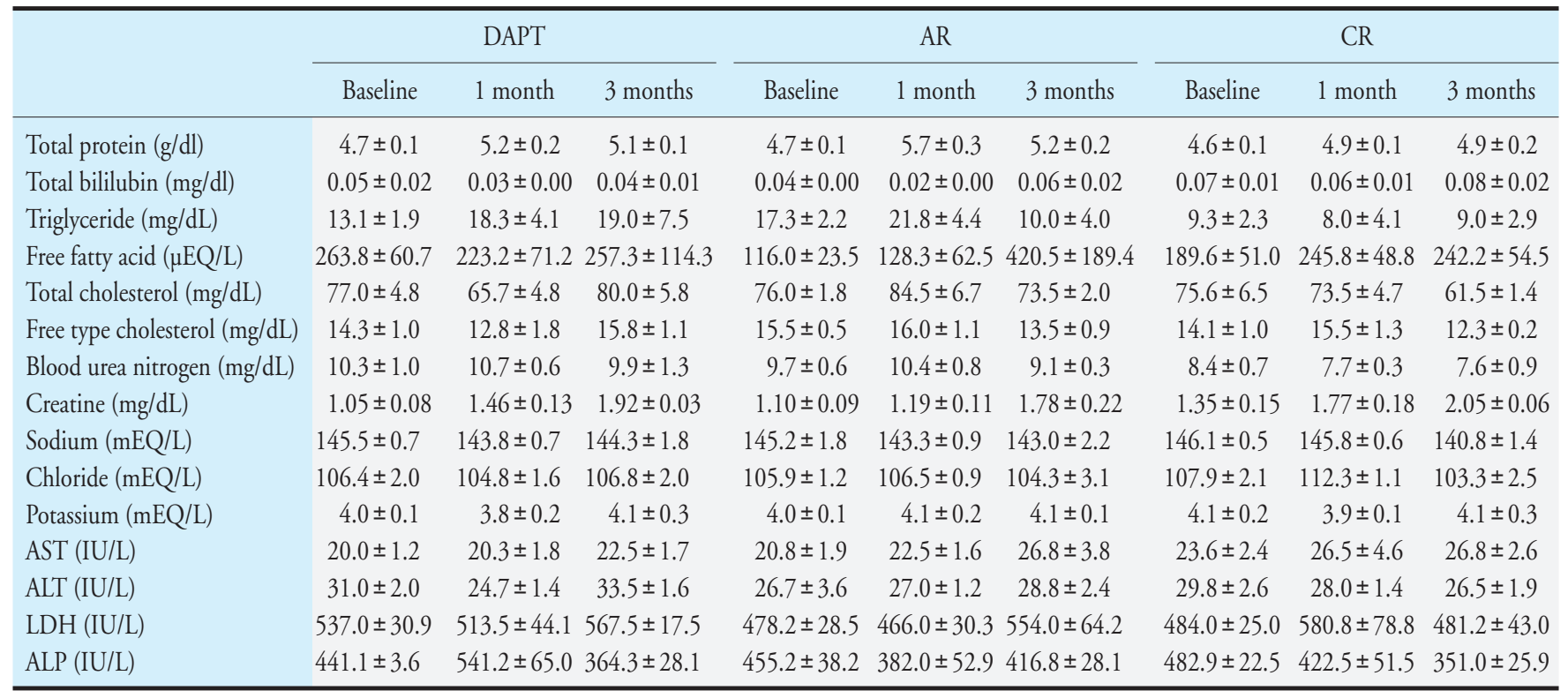

Data are presented as mean \pm standard error of the mean. AST, asparate aminotransferase; ALT, alanine aminotrasferase; LDH, lactate dehydrogenase; ALP, alkaline phosphoatase; DAPT, dual antiplatelet therapy (consinting of aspirin and clopidogrel); AR, aspirin and rivaroxaban; CR, clopidogrel and rivaroxaban.

heterogeneous patterns and the lowest proportion of layered patterns. At 3 months, the proportions of neointimal patterns were comparable among the three groups. With regard to neointimal thickness at the stent struts, the DAPT group showed the lowest neointimal thickness at 1 month; however, at 3 months, this had increased to be comparable with the other two groups. In the $\mathrm{AR}$ and $\mathrm{CR}$ groups, the neointimal thickness was similar between 1 and 3 months (Fig. 3C, 3D, and Table 2). Similar to the neointimal thickness, the DAPT group also showed the smallest neointimal area at 1 month (Fig. $3 \mathrm{E}$ and Table 2). At 3 months, although the neointimal area values were similar in the three groups, the statistical analysis revealed a significantly larger area in the $\mathrm{CR}$ group than in the DAPT group $\left(2.48 \mathrm{~mm}^{2}\right.$ in CR versus $2.44 \mathrm{~mm}^{2}$ in DAPT, $\left.p=0.045\right)$. In the AR and CR groups, the neointimal area was similar between 1 and 3 months (Fig.3E, 3F, and Table 2).

\section{Histological Findings}

Vessel injury scores were comparable among the three groups at both 1 and 3 months (Table 3 ). The neointimal area was comparable among the three groups at 1 month; however, this value was smallest in the CR group at 3 months (Fig. 5A, 5B, and Table 3). The neointimal area in the DAPT and AR groups increased from 1 to 3 months, whereas that in the CR group remained similar.

The proportion of SMCs with contractile features, which indicates stable status, was significantly greater in the CR group at both 1 and 3 months (Fig.4, Fig. 5C-D, and Table 3). Fibrin deposition around the stent struts tended to be greater in the AR and CR groups at 1 month and comparable among the three groups at 3 months (Table 3 ). The semiquantitative inflammation score tended to be lower in the CR group at 1 month and comparable among the three groups at 3 months (Table 3). In-stent thrombi were more frequent in the AR at 1 month, whereas the incidence between CR and DAPT, as well as CR and AR, was comparable (Fig. 5E); however, no in-stent thrombi were seen in any of the three groups at 3 months.

\section{Discussion}

In this study, we demonstrated the in-stent responses to a dual therapy of antiplatelet drugs and the FXa inhibitor rivaroxaban after DES implantation using intracoronary imaging analysis and histological examination. Our study revealed evidence supporting the noninferiority of combination therapy using rivaroxaban with an antiplatelet drug, particularly the dual therapy of clopidogrel and rivaroxaban, compared with traditional aspirin/clopidogrel therapy after DES implantation in a porcine coronary artery. Therefore, our results provide pathological evidence verifying the efficacy of the combination of a $\mathrm{P}_{2} \mathrm{Y}_{12}$ receptor antagonist with the direct FXa inhibitor rivaroxaban 


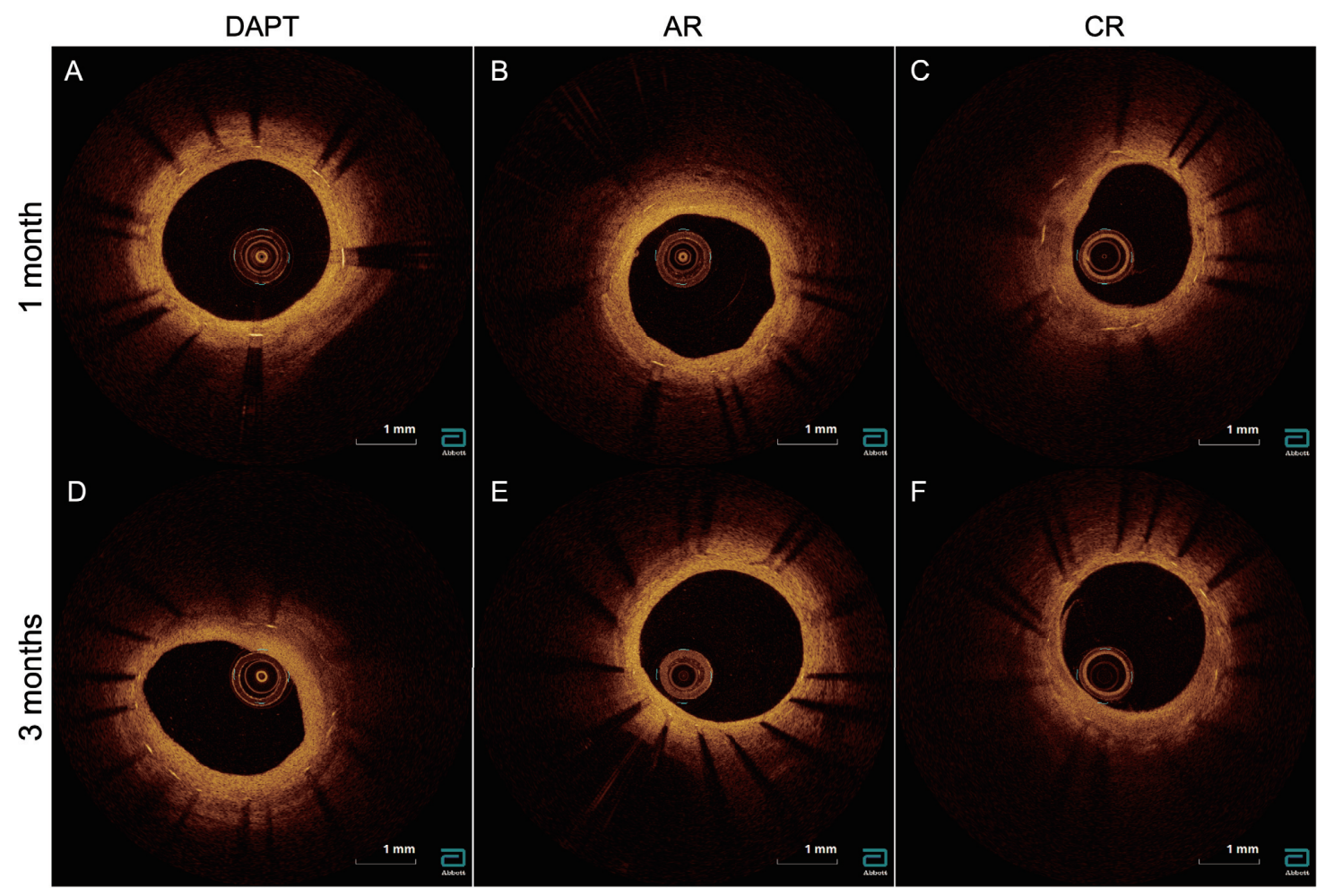

Fig. 2. Representative cases of optical coherence tomography findings

The upper panel shows cross-sectional images of a coronary artery at 1 month after EES implantation: (A) DAPT, (B) AR, and (C) CR. The lower panel shows cross-sectional images of a coronary artery at 3 months after EES implantation: (D) DAPT, (E) AR, and (F) CR.

EES, everolimus-eluting stent; DAPT, dual antiplatelet therapy (consisting of aspirin and clopidogrel administration); AR, aspirin and rivaroxaban; CR, clopidogrel and rivaroxaban

in previous clinical trials in AF patients after DES implantation.

Mechanical injury of the endothelium after stent implantation causes the activation of the coagulation system $^{28)}$, while the exposure of stent struts to the blood flow causes turbulence and activates coagulation $^{29)}$. Various molecular pathways, through platelet and coagulation cascades, are strongly associated with neointimal hyperplasia after stent implantation ${ }^{30,31)}$. Previous preclinical studies have shown that the FXa inhibitor, rivaroxaban, suppresses stent thrombi ${ }^{10)}$, while the inhibition of the FXa pathway suppresses neointimal hyperplasia after vascular injury ${ }^{32,33)}$. In particular, FXa-proteaseactivated receptor signaling may play an important role in these pathophysiological findings $\left.{ }^{34,} 35\right)$; therefore, rivaroxaban might have a beneficial effect on both in-stent thrombosis and neointimal hyperplasia after DES implantation. In this study, results including the smaller pathological neointimal area at 3 months, the proportionally greater area of SMCs with contractile features at 1 and 3 months, and fewer in-stent thrombi at 1 month using a dual therapy of clopidogrel and rivaroxaban (CR group) made this therapy more effective than dual therapy using aspirin and rivaroxaban (AR group). Dual therapy using aspirin and rivaroxaban did not show sufficient antithrombotic effects when compared with DAPT; this indicates that a combination of aspirin and OAC is not sufficient, as previously reported ${ }^{36)}$. On the other hand, CR treatment was similar to DAPT and could suppress in-stent thrombi. This may be due to the strong antiplatelet effect of clopidogrel as an adenosine diphosphate-P2 $\mathrm{Y}_{12}$ receptor antagonist ${ }^{37)}$. Furthermore, the anti-inflammatory effect of clopidogrel might contribute to the tendency toward a lower inflammation score at 1 month in the CR group ${ }^{38)}$. Especially, these results indicate that the dual therapy of clopidogrel and rivaroxaban might be an effective antithrombotic therapy after DES implantation.

A previous porcine study revealed that neointimal growth reached a peak at 3 months after coronary artery DES implantation; this was maintained until 6 months, after which, neointimal growth began to decline ${ }^{39)}$. In our DES implantation model, the neointima had fully covered the surface of the DES at both 1 and 3 months in all three groups.

\section{Advance Publication Journal of Atherosclerosis and Thrombosis}


A
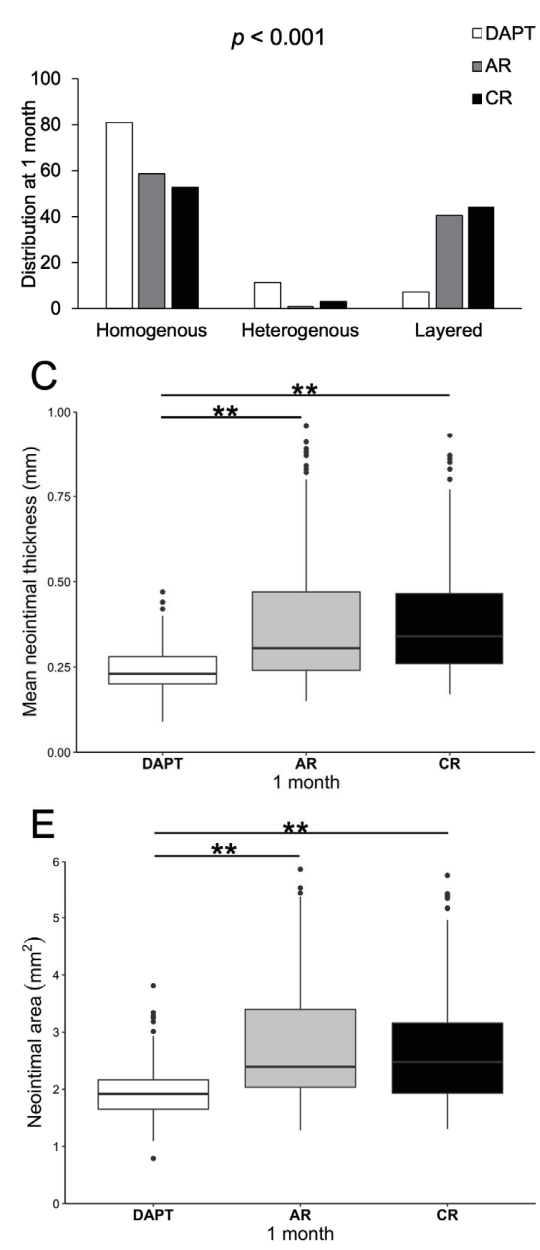

B
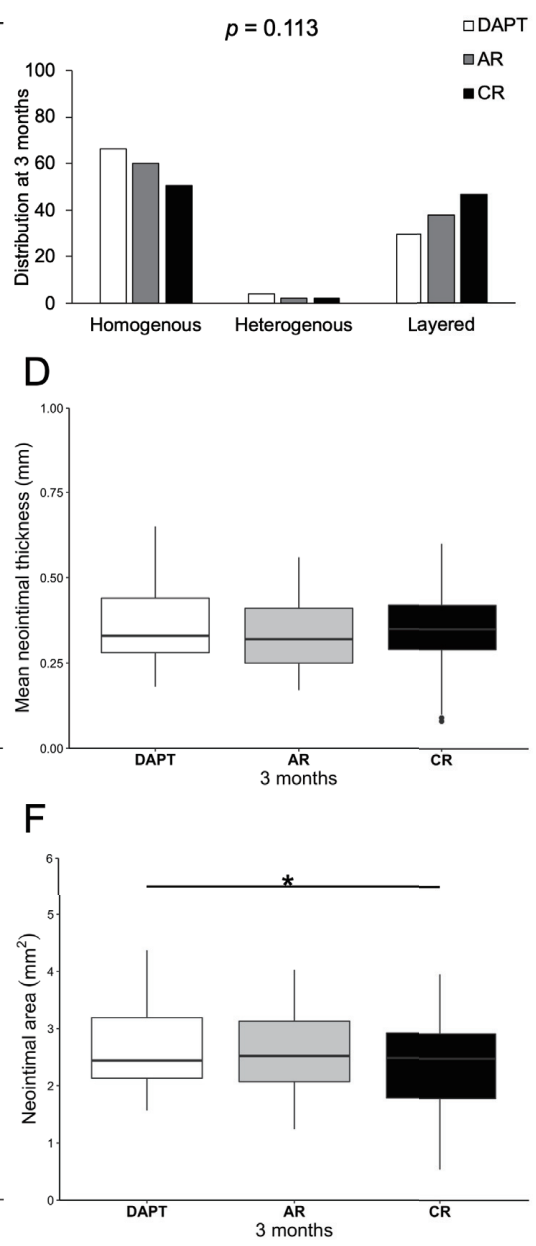

Fig.3. Quantitative analysis of optical coherence tomography findings

Distribution of neointimal characteristics at (A) 1 month after EES implantation and (B) 3 months after EES implantation. Comparison of mean neointimal thickness in the three groups at (C) 1 and (D) 3 months after EES implantation. Comparison of the neointimal area in the three groups at (E) 1 and (F) 3 months after EES implantation. Data are expressed as median (IQR). *indicates a $p$-value less than 0.05 ; ** indicates a $p$-value less than 0.001 .

EES, everolimus-eluting stent; IQR, interquartile range; DAPT, dual antiplatelet therapy (consisting of aspirin and clopidogrel administration); $\mathrm{AR}$, aspirin and rivaroxaban; $\mathrm{CR}$, clopidogrel and rivaroxaban

However, the patterns of vascular response after DES implantation were somewhat different among the three groups. Despite inconsistencies between OCT and pathological results regarding the measurement of the intimal thickness and area, both OCT and pathological results indicated a different time course for neointimal growth between DAPT and AR or CR treatments. In the DAPT group, as reported in a previous study ${ }^{39)}$, the neointima continued to grow from 1 to 3 months. However, in the CR group, the neointima grew rapidly and reached its peak within 1 month; subsequently, the neointima almost stopped growing and was maintained until 3 months (Fig.3, Fig. 5, Table 2, and Table 3). The shortened time course of neointimal growth may be favorable for rapid neointimal stability and quick vascular healing. The inconsistencies between the OCT and pathological results regarding the measurements of the intimal thickness and area might be due to the small sample size, resolution of OCT, and distortion of the tissue-stent interface during pathological processing. As the neointimal thickness was measured only at the stent struts, a lack of information on neointimal hyperplasia between struts makes its evaluation function different from that of the neointimal area.

The DAPT group showed a different distribution of the three neointimal OCT pattern types between 1 and 3 months, while there was a similar distribution between 1 and 3 months in the AR and CR groups. This was consistent with the abovementioned data 
Table 2. Comparison of OCT findings between three groups

$p$-value

DAPT AR CR Overall DAPT vs AR DAPT vs CR AR vs CR

\begin{tabular}{|c|c|c|c|c|c|c|c|}
\hline \multicolumn{8}{|l|}{ At 1 month } \\
\hline Mean neointimal thickness (mm) & $0.23[0.20,0.28]$ & $0.30[0.24,0.47]$ & $0.34[0.26,0.46]$ & 0.000 & 0.000 & 0.000 & 0.310 \\
\hline Neointinal area $\left(\mathrm{mm}^{2}\right)$ & $1.92[1.65,2.17]$ & $2.40[2.04,3.40]$ & $2.48[1.93,3.16]$ & 0.000 & 0.000 & 0.000 & 0.650 \\
\hline Homogeneous (\%) & 81.1 & 58.6 & 51.1 & $<0.001$ & 0.000 & 0.000 & NS \\
\hline Heterogeneous (\%) & 11.3 & 0.9 & 4.3 & & 0.000 & NS & NS \\
\hline Layered $(\%)$ & 7.5 & 40.5 & 44.7 & & 0.000 & 0.000 & NS \\
\hline \multicolumn{8}{|l|}{ At 3 months } \\
\hline Mean neointimal thickness (mm) & $0.33[0.28,0.44]$ & $0.32[0.25,0.41]$ & $0.35[0.29,0.42]$ & 0.301 & NA & NA & NA \\
\hline Neointinal area $\left(\mathrm{mm}^{2}\right)$ & $2.44[2.13,3.19]$ & $2.52[2.07,3.13]$ & $2.48[1.79,2.92]$ & 0.021 & 0.459 & 0.045 & 0.061 \\
\hline Homogeneous (\%) & 66.3 & 60.2 & 50.8 & 0.113 & NA & NA & NA \\
\hline Heterogeneous (\%) & 4.0 & 2.2 & 2.3 & & NA & NA & NA \\
\hline Layered (\%) & 29.7 & 37.6 & 46.9 & & NA & NA & NA \\
\hline
\end{tabular}

Data are presented as median [interquartile range] or number. OCT, optical coherence tomogoraphy; DAPT, dual-antiplatelet therapy (consisting of aspirin and colopidogrel); $\mathrm{AR}$, aspirn and rivaroxaban; $\mathrm{CR}$, clopidogrel and rivaroxaban.

Table 3. Comparison of histological findings between three groups

$$
p \text {-value }
$$

\begin{tabular}{|c|c|c|c|c|c|c|c|}
\hline & DAPT & $\mathrm{AR}$ & CR & Overall & DAPT vs AR & DAPT vs CR & AR vs $\mathrm{CR}$ \\
\hline \multicolumn{8}{|l|}{ At 1 month } \\
\hline Neointimal area $\left(\mathrm{mm}^{2}\right)$ & $1.75[1.52,2.16]$ & $1.81[1.59,2.21]$ & $2.13[1.77,2.96]$ & 0.398 & NA & NA & NA \\
\hline Proportion of cSMC area (\%) & $33.9 \pm 3.1$ & $12.3 \pm 2.4$ & $43.2 \pm 4.2$ & 0.000 & 0.000 & 0.121 & 0.000 \\
\hline Fibrin deposition area $\left(\mu \mathrm{m}^{2}\right)$ & $1971.4[1767.3,2922.8]$ & $3771.0[2047.3,6102.2]$ & $3895.2[2957.6,5834.4]$ & 0.059 & NA & NA & NA \\
\hline Inflammation score & $1.07 \pm 0.08$ & $1.33 \pm 0.14$ & $0.91 \pm 0.13$ & 0.054 & NA & NA & NA \\
\hline Vessel injuly score & $0.95 \pm 0.07$ & $0.87 \pm 0.08$ & $1.02 \pm 0.09$ & 0.462 & NA & NA & NA \\
\hline \multicolumn{8}{|l|}{ At 3 months } \\
\hline Neointimal area $\left(\mathrm{mm}^{2}\right)$ & $2.47[2.42,2.89]$ & $2.32[1.92,2.83]$ & $2.05[1.80,2.29]$ & 0.016 & 0.401 & 0.004 & 0.401 \\
\hline Proportion of cSMC area (\%) & $47.5 \pm 3.1$ & $33.2 \pm 1.9$ & $60.9 \pm 3.2$ & 0.000 & 0.002 & 0.004 & 0.000 \\
\hline Fibrin deposition area $\left(\mu \mathrm{m}^{2}\right)$ & $273.3[56.9,520.1]$ & $15.7[0.0,106.3]$ & $93.0[0.0,260.1]$ & 0.137 & NA & NA & NA \\
\hline Inflammation score & $1.04 \pm 0.13$ & $1.08 \pm 0.12$ & $1.32 \pm 0.11$ & 0.209 & NA & NA & NA \\
\hline Vessel injuly score & $1.17 \pm 0.07$ & $1.08 \pm 0.07$ & $1.25 \pm 0.08$ & 0.314 & NA & NA & NA \\
\hline
\end{tabular}

Data are presented as mean \pm standard error of the mean or median [interquartile range]. DAPT, dual antiplatelet therapy (consinting of aspirin and clopidogrel); AR, aspirina and rivaroxaban; CR, clopidogrel and rivaroxaban; cSMC, contractile soomth muscle cell.

regarding neointimal growth and indicated different time courses for vascular response between DAPT and $\mathrm{CR}$ or AR treatments. Since the heterogeneous pattern is thought to be linked to poor long-term prognoses ${ }^{40-42)}$, a lower proportion of heterogeneous patterns in AR and CR might indicate a beneficial effect. The high proportion of layered patterns in the $\mathrm{AR}$ and $\mathrm{CR}$ groups at 1 month might reflect a clearer boundary between SMCs with contractile and synthetic features.

SMC heterogeneity has been described in atherosclerotic lesions and restenosis after angioplasty or stenting ${ }^{21-23)}$. Consistent with previous studies, two types of SMCs were distinguished in the neointima after DES implantation: SMCs with contractile features and SMCs with synthetic features. With less proliferation, lower ECM production, and rich, tightly aligned contractile filaments, SMCs with contractile features are considered mature and stable ${ }^{24)}$, playing a beneficial role after DES implantation. The proportionally greater number of SMCs with contractile features in the CR group at both 1 and 3 months indicated a rapid and more stabilized in-stent neointimal environment using a dual therapy of clopidogrel and rivaroxaban.

Recent clinical trials have demonstrated that rivaroxaban reduces mortality and cardiovascular events, including stent thrombosis, in patients with

\section{Advance Publication Journal of Atherosclerosis and Thrombosis}



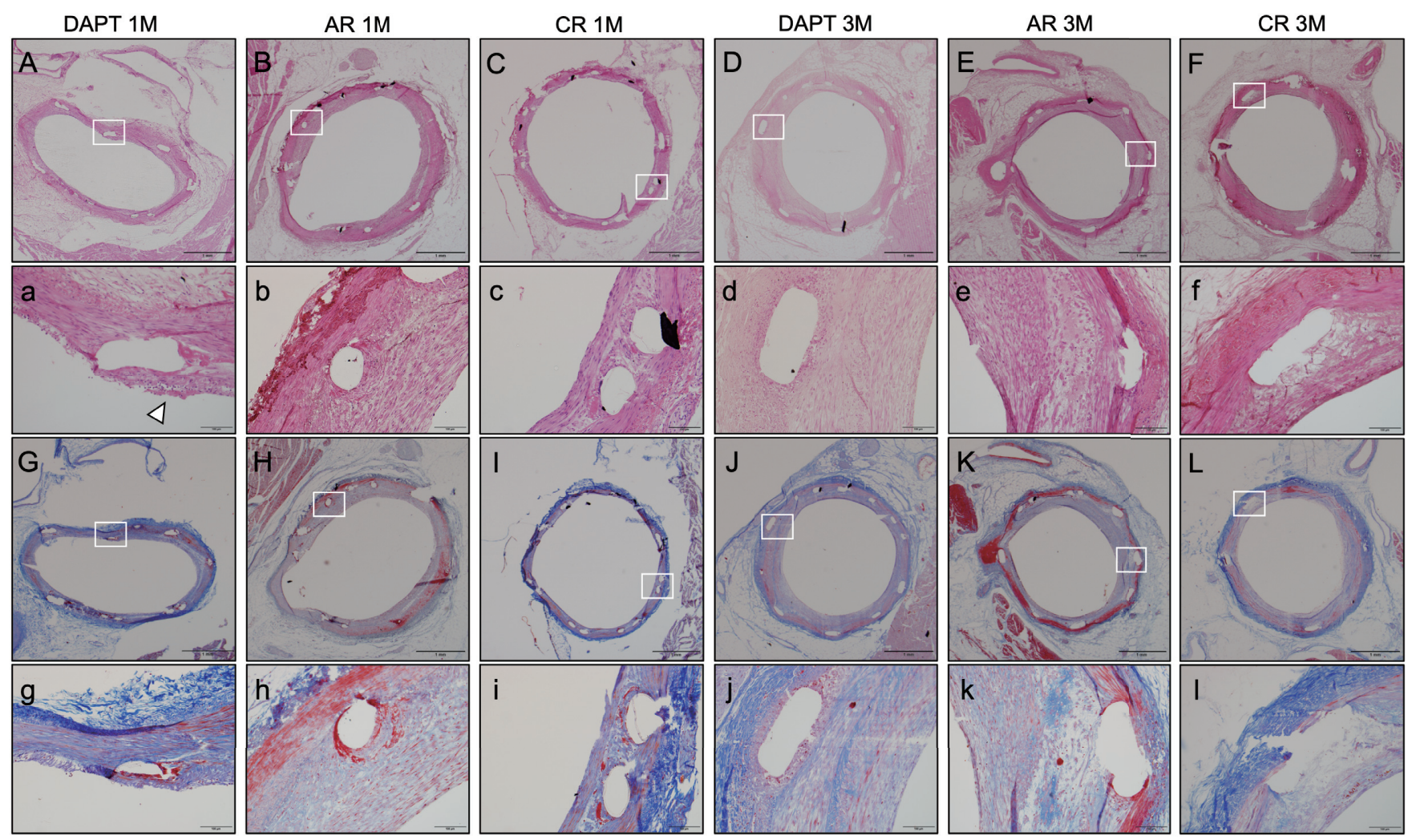

Fig.4. Histological findings

(A-C) Coronary artery walls stained via HE staining and (G-I) corresponding MT-stained tissues at 1 month in the three groups (A, G: DAPT; B, H: AR; and C, I: CR). (D-F) Coronary artery walls stained via HE staining and (J-L) corresponding MT-stained tissues at 3 months in the three groups (D, J: DAPT; E, K: AR; and F, L: CR). (a-l) Magnified images corresponding to the white square in the upper panel of $\mathrm{A}-\mathrm{L}$; the white arrow in panel a indicates an in-stent thrombus.

HE, hematoxylin and eosin; MT, Masson's trichrome; DAPT, dual antiplatelet therapy (consisting of aspirin and clopidogrel administration); $\mathrm{AR}$, aspirin and rivaroxaban; $\mathrm{CR}$, clopidogrel and rivaroxaban

acute coronary syndrome $\left.{ }^{4,43}, 44\right)$. A previous study showed that aspirin and rivaroxaban therapy could lead to better cardiovascular outcomes than aspirin alone $^{45)}$. Moreover, combination therapy using P2Y 12 receptor antagonists and FXa inhibitors may have more benefits related to clinical efficacy ${ }^{46,47)}$. Our study is consistent with previous clinical results and provides supporting evidence of a pathological vascular response for the results of these clinical trials. The shortened time course of neointimal growth and the increased number of mature/stable SMC with CR dual therapy indicated quick vascular healing and might contribute to the shortening of the administration period of antiplatelet drugs and DOACs.

\section{Study Limitations}

Our study has some limitations; this study was performed using a healthy coronary animal model. In brief, we implanted a stent in a healthy coronary artery and not in one that had developed atherosclerosis; therefore, the reaction to antiplatelet drugs and anticoagulants may be different in actual atherosclerotic lesions. However, as our results reflected a fundamental vessel response after mechanical injury with DES implantation, they are considered a meaningful examination of the effect of antiplatelet drugs and DOACs on neointimal progression and thrombus formation. In this study, given that only a single dose of rivaroxaban could be tested, the dose-response relationship for rivaroxaban in a swine cardiovascular system remains unclear. Since the biological responses between pigs and humans are different (more specifically, the reaction in pigs is more rapid than that in humans ${ }^{48)}$ ), our results cannot precisely predict the optimal duration of antithrombotic therapy in clinical practice. It would, therefore, be meaningful to perform long-term observations that exceed 6 months, to verify the peak of neointimal hyperplasia and prove the noninferiority or benefit of $\mathrm{CR}$ or $\mathrm{AR}$ treatment regarding neointimal growth and vascular healing. However, the 

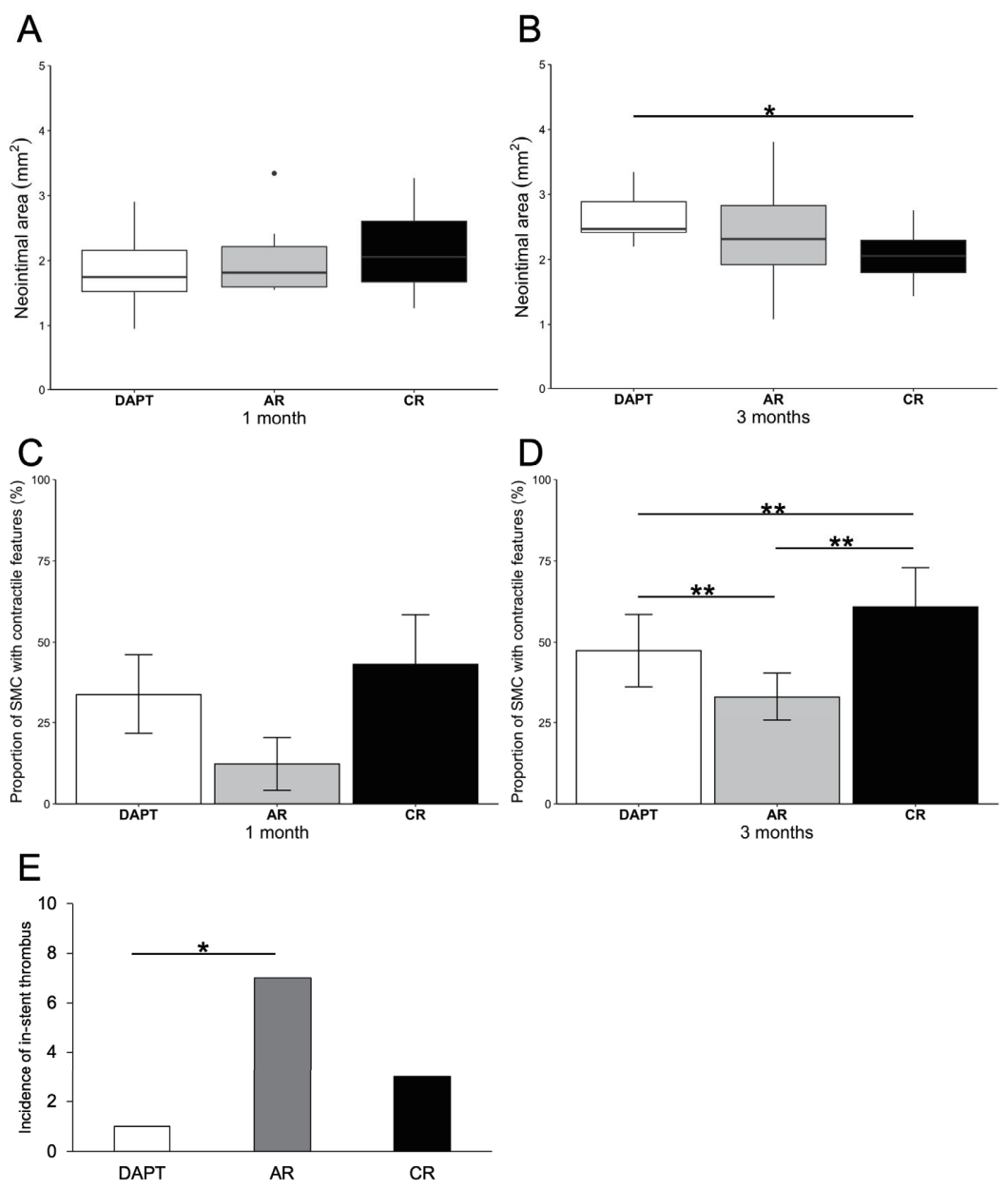

Fig. 5. Quantitative analysis of the histological findings

(A-B) Neointimal areas in the three groups are shown at (A) 1 and (B) 3 months. (C-D) The proportion of SMCs with contractile features in the three groups, calculated using the morphometrically traced area of the layer containing SMCs with contractile features divided by the total neointimal area, is shown at (C) 1 and (D) 3 months. (E) The incidence of in-stent thrombi in 15 segments each at 1 month after everolimuseluting stent implantation in the three groups. Data are expressed as median (IQR) or mean \pm SEM as appropriate. *indicates a $p$-value less than $0.05 ; *$ indicates a $p$-value less than 0.001 .

SMC, smooth muscle cell; IQR, interquartile range; SEM, standard error of the mean; DAPT, dual antiplatelet therapy (consisting of aspirin and clopidogrel administration); AR, aspirin and rivaroxaban; CR, clopidogrel and rivaroxaban

long-term observation of pigs is difficult due to their rapid increase in both size and body weight; miniature pigs may, thus, be more suitable for long-term observation. Since immunostaining was not performed in this study, it was difficult to identify detailed cell types such as macrophages, lymphocytes, and fibroblasts in the neointima.

\section{Conclusion}

Our results proved the noninferiority of the combination of rivaroxaban with an antiplatelet drug, particularly dual therapy using rivaroxaban and clopidogrel, compared with traditional DAPT after
DES implantation. The patterns of vascular response were distinct, depending on the different drug combinations. The shortened time course of neointimal growth and the predominantly stable type of SMCs with CR dual therapy indicated quick vascular healing and may contribute to the shortening of the administration period for antiplatelet drugs and DOACs.

\section{Acknowledgements}

The authors sincerely thank Ms. Emi Tashiro and Ms. Sachi Nishitani for their excellent assistance with the experiments. 
The Division of Advanced Cardiovascular Imaging is an endowment department, supported by an unrestricted grant from Active Medical Co., Ltd, Boston Scientific Japan Co., Ltd, Hokushin Medical Co., Ltd., and Otsuka Pharmaceutical Co., Ltd.

\section{Funding Sources}

This work was partly supported by a research foundation from Bayer Yakuhin Ltd. The funder had no role in finalizing the study design, data collection and analysis, and decision to publish.

\section{Disclosure}

D.K. has received research funding from DaiichiSankyo. T.H. has received lecture fees from Bayer Yakuhin. Y.O. has received lecture fees from Bayer Yakuhin and Daiichi-Sankyo; research funding from Bayer Yakuhin and Bristol-Myers Squibb; and scholarship grants from Bayer Yakuhin, DaiichiSankyo, and Johnson \& Johnson. A.H. has received lecture fees from Amgen Astellas BioPharma, Astellas Pharma, Bayer Yakuhin, Boehringer Ingelheim, Boston Scientific Japan, Bristol-Myers Squibb, Daiichi-Sankyo, Sanofi, Sumitomo Dainippon Pharma, Takeda Pharmaceutical, Toa Eiyo, and Otsuka Pharmaceutical.

\section{References}

1) Singh I, Shafiq N, Pandhi P, Reddy S, Pattanaik S, Sharma Y, Malhotra S: Triple antiplatelet therapy vs. dual antiplatelet therapy in patients undergoing percutaneous coronary intervention: an evidence-based approach to answering a clinical query. Br J Clin Pharmacol, 2009; 68: 4-13

2) Harper RW: Drug-eluting coronary stents--a note of caution. Med J Aust, 2007; 186: 253-255

3) Dewilde WJM, Oirbans T, Verheugt FWA, Kelder JC, De Smet BJGL, Herrman J-P, Adriaenssens T, Vrolix M, Heestermans AACM, Vis MM, Tijsen JGP, van't Hof AW, ten Berg JM, WOEST study investigators: Use of clopidogrel with or without aspirin in patients taking oral anticoagulant therapy and undergoing percutaneous coronary intervention: an open-label, randomised, controlled trial. Lancet, 2013; 381: 1107-1115

4) Mega JL, Braunwald E, Wiviott SD, Bassand J-P, Bhatt DL, Bode C, Burton P, Cohen M, Cook-Bruns N, Fox KAA, Goto S, Murphy SA, Plotnikov AN, Schneider D, Sun X, Verheugt FWA, Gibson CM, ATLAS ACS 2TIMI 51 Investigators: Rivaroxaban in patients with a recent acute coronary syndrome. N Engl J Med, 2012; 366: 9-19

5) Gibson CM, Pinto DS, Chi G, Arbetter D, Yee M, Mehran R, Bode C, Halperin J, Verheugt FWA, Wildgoose P, Burton P, van Eickels M, Korjian S, Daaboul
Y, Jain P, Lip GYH, Cohen M, Peterson ED, Fox KAA: Recurrent hospitalization among patients with atrial fibrillation undergoing intracoronary stenting treated with 2 treatment strategies of rivaroxaban or a doseadjusted oral vitamin $\mathrm{K}$ antagonist treatment strategy. Circulation, 2017; 135: 323-333

6) Cannon CP, Bhatt DL, Oldgren J, Lip GYH, Ellis SG, Kimura T, Maeng M, Merkely B, Zeymer U, Gropper S, Nordaby M, Kleine E, Harper R, Manassie J, Januzzi JL, ten Berg JM, Steg PG, Hohnloser SH, RE-DUAL PCI Steering Committee and Investigators: Dual antithrombotic therapy with dabigatran after PCI in atrial fibrillation. N Engl J Med, 2017; 377: 1513-1524

7) Gibson CM, Mehran R, Bode C, Halperin J, Verheugt FW, Wildgoose P, Birmingham M, Ianus J, Burton P, van Eickels M, Korjian S, Daaboul Y, Lip GYH, Cohen M, Husted S, Peterson ED, Fox KA: Prevention of bleeding in patients with atrial fibrillation undergoing PCI. N Engl J Med, 2016; 375: 2423-2434

8) Lopes RD, Heizer G, Aronson R, Vora AN, Massaro T, Mehran R, Goodman SG, Windecker S, Darius H, Li J, Averkov O, Bahit MC, Berwanger O, Budaj A, Hijazi Z, Parkhomenko A, Sinnaeve P, Storey RF, Thiele H, Vinereanu D, Granger CB, Alexander JH, AUGUSTUS Investigators: Antithrombotic therapy after acute coronary syndrome or PCI in atrial fibrillation. N Engl J Med, 2019; 380: 1509-1524

9) Lopes RD, Hong H, Harskamp RE, Bhatt DL, Mehran R, Cannon CP, Granger CB, Verheugt FWA, Li J, ten Berg JM, Sarafoff N, Gibson CM, Alexander JH: Safety and efficacy of antithrombotic strategies in patients with atrial fibrillation undergoing percutaneous coronary intervention: A network meta-analysis of randomized controlled trials. JAMA Cardiol, 2019; 4: 747-755

10) Becker EM, Perzborn E, Klipp A, Lücker C, Bütehorn U, Kast R, Badimon JJ, Laux V: Effects of rivaroxaban, acetylsalicylic acid and clopidogrel as monotherapy and in combination in a porcine model of stent thrombosis. J Thromb Haemost, 2012; 10: 2470-2480

11) Kubo T, Akasaka T, Kozuma K, Kimura K, Kawamura M, Sumiyoshi T, Ino Y, Morino Y, Tanabe K, Kadota K, Kimura T, RESET Investigators: Comparison of neointimal coverage between everolimus-eluting stents and sirolimus-eluting stents: an optical coherence tomography substudy of the RESET (Randomized Evaluation of Sirolimus-eluting versus Everolimus-eluting stent Trial). EuroIntervention, 2015; 11: 564-571

12) Kim J-S, Afari ME, Ha J, Tellez A, Milewski K, Conditt G, Cheng Y, Hua Yi G, Kaluza GL, Granada JF: Neointimal patterns obtained by optical coherence tomography correlate with specific histological components and neointimal proliferation in a swine model of restenosis. Eur Heart J Cardiovasc Imaging, 2014; 15: 292-298

13) Tanigawa J, Barlis P, Di Mario C: Intravascular optical coherence tomography: optimisation of image acquisition and quantitative assessment of stent strut apposition. EuroIntervention, 2007; 3: 128-136

14) Malik N, Gunn J, Holt C, Shepherd L, Francis S, Newman C, Crossman D, Cumberland D: Intravascular stents: a new technique for tissue processing for histology, 
immunohistochemistry, and transmission electron microscopy. Heart, 1998; 80: 509-516

15) Rippstein P, Black MK, Boivin M, Veinot JP, Ma X, Chen Y-X, Human P, Zilla P, O’Brien ER: Comparison of processing and sectioning methodologies for arteries containing metallic stents. J Histochem Cytochem, 2006; 54: 673-681

16) Schwartz RS, Edelman ER, Carter A, Chronos N, Rogers C, Robinson KA, Waksman R, Weinberger J, Wilensky RL, Jensen DN, Zuckerman BD, Virmani R, Consensus Committee: Drug-eluting stents in preclinical studies: recommended evaluation from a consensus group. Circulation, 2002; 106: 1867-1873

17) Schneider CA, Rasband WS, Eliceiri KW: NIH Image to ImageJ: 25 years of image analysis. Nat Methods, 2012; 9: 671-675

18) Schwartz RS, Huber KC, Murphy JG, Edwards WD, Camrud AR, Vlietstra RE, Holmes DR: Restenosis and the proportional neointimal response to coronary artery injury: Results in a porcine model. J Am Coll Cardiol, 1992; 19: 267-274

19) Hofma SH, Whelan DMC, van Beusekom HMM, Verdouw PD, van der Giessen WJ: Increasing arterial wall injury after long-term implantation of two types of stent in a porcine coronary model. Eur Heart J, 1998; 19: 601609

20) Mori M, Sakata K, Nakanishi C, Nakahashi T, Kawashiri M, Yoshioka K, Takuwa Y, Okada H, Yokawa J, Shimojima M, Yoshimuta T, Yoshida S, Yamagishi M, Hayashi K: Early endothelialization associated with a biolimus A9 bioresorbable polymer stent in a porcine coronary model. Heart Vessels, 2017; 32: 1244-1252

21) Orlandi A, Ehrlich HP, Ropraz P, Spagnoli L G, Gabbiani G: Rat aortic smooth muscle cells isolated from different layers and at different times after endothelial denudation show distinct biological features in vitro. Arterioscler Thromb, 1994; 14: 982-989

22) Hao H, Gabbiani G, Bochaton-Piallat ML: Arterial smooth muscle cell heterogeneity: implications for atherosclerosis and restenosis development. Arterioscler Thromb Vasc Biol, 2003; 23: 1510-1520

23) Escuer J, Martínez MA, McGinty S, Peña E: Mathematical modelling of the restenosis process after stent implantation. J R Soc Interface, 2019; 16: 20190313

24) Rensen SSM, Doevendans PAFM, van Eys GJJM: Regulation and characteristics of vascular smooth muscle cell phenotypic diversity. Neth Heart J, 2007; 15: 100108

25) Turley EA: Extracellular matrix remodeling: Multiple paradigms in vascular disease. Circ Res, 2001; 88: 2-4

26) Sugita S, Mizutani E, Hozaki M, Nakamura M, Matsumoto T: Photoelasticity-based evaluation of cellular contractile force for phenotypic discrimination of vascular smooth muscle cells. Sci Rep, 2019; 9: 3960

27) Kawakami R, Hao H, Imanaka T, Shibuya M, Ueda Y, Tsujimoto M, Ishibashi-Ueda $\mathrm{H}$, Hirota $\mathrm{S}$ : Initial pathological responses of second-generation everolimuseluting stents implantation in Japanese coronary arteries: Comparison with first-generation sirolimus-eluting stents. J Cardiol, 2018; 71: 452-457
28) Costa MA, Simon DI: Molecular basis of restenosis and drug-eluting stents. Circulation, 2005; 111: 2257-2273

29) Pearson JD: Endothelial cell function and thrombosis. Baillieres Clin Haematol, 1994; 7: 441-452

30) Toutouzas K, Colombo A, Stefanadis C: Inflammation and restenosis after percutaneous coronary interventions. Eur Heart J, 2004; 25: 1679-1687

31) Chandrasekar B, Tanguay JF: Platelets and restenosis. J Am Coll Cardiol, 2000; 35: 555-562

32) Ragosta M, Gimple LW, Gertz SD, Dunwiddie CT, Vlasuk GP, Haber HL, Powers ER, Roberts WC, Sarembock IJ: Specific factor Xa inhibition reduces restenosis after balloon angioplasty of atherosclerotic femoral arteries in rabbits. Circulation, 1994; 89: 1262 1271

33) Kaiser B, Paintz M, Scholz O, Kunitada S, Fareed J: A synthetic inhibitor of factor Xa, DX-9065a, reduces proliferation of vascular smooth muscle cells in vivo in rats. Thromb Res, 2000; 98: 175-185

34) Cheung WM, D'Andrea MR, Andrade-Gordon P, Damiano BP: Altered vascular injury responses in mice deficient in protease-activated receptor-1. Arterioscler Thromb Vasc Biol, 1999; 19: 3014-3024

35) Damiano BP, D’Andrea MR, de Garavilla L, Cheung WM, Andrade-Gordon P: Increased expression of protease activated receptor-2 (PAR-2) in balloon-injured rat carotid artery. Thromb Haemost, 1999; 81: 808-814

36) Leon MB, Baim DS, Popma JJ, Gordon PC, Cutlip DE, Ho KKL, Giambartolomei A, Diver DJ, Lasorda DM, Williams DO, Pocock SJ, Kuntz RE: A clinical trial comparing three antithrombotic-drug regimens after coronary-artery stenting. N Engl J Med, 1998; 339: $1665-1671$

37) Dorsam RT, Murugappan S, Ding Z, Kunapuli SP: Clopidogrel: interactions with the $\mathrm{P}_{2} \mathrm{Y}_{12}$ receptor and clinical relevance. Hematology, 2003; 8: 359-365

38) Li M, Zhang Y, Ren H, Zhang Y, Zhu X: Effect of clopidogrel on the inflammatory progression of early atherosclerosis in rabbits model. Atherosclerosis, 2007; 194: 348-356

39) Virmani R, Kolodgie FD, Farb A, Lafont A: Drug eluting stents: are human and animal studies comparable? Heart, 2003; 89: 133-138

40) Kilickesmez K, Dall'Ara G, Rama-Merchan JC, Ghione M, Mattesini A, Vinues CM, Konstantinidis N, Pighi M, Estevez-Loureiro R, Zivelonghi C, Lindsay AC, Secco GG, Foin N, De Silva R, Di Mario C: Optical coherence tomography characteristics of in-stent restenosis are different between first and second generation drug eluting stents. Int J Cardiol Heart Vessels, 2014; 3: 68-74

41) Shi S-Y, Chen K-L, Gu J, Xu C, Chen Q-R, Chen Y-Q, $\mathrm{Xu}$ T, Ke H-Y, Sun J-H, Ye F: Correlation between preprocedural plaque morphology and patterns of in-stent neointimal hyperplasia at 1-year follow-up in patients treated with new-generation drug-eluting stents: An optical coherence tomography based analysis. J Interv Cardiol, 2018; 31: 737-746

42) Kim J-S, Lee J-H, Shin D-H, Kim B-K, Ko Y-G, Choi D, Jang Y, Hong M-K: Long-term outcomes of neointimal hyperplasia without neoatherosclerosis after drug-eluting stent implantation. JACC Cardiovasc Imaging, 2014; 7: 
788-795

43) Gibson CM, Chakrabarti AK, Mega J, Bode C, Bassand J-P, Verheugt FWA, Bhatt DL, Goto S, Cohen M, Mohanavelu S, Burton P, Stone G, Braunwald E, ATLASACS 2 TIMI 51 Investigators: Reduction of stent thrombosis in patients with acute coronary syndromes treated with rivaroxaban in ATLAS-ACS 2 TIMI 51. J Am Coll Cardiol, 2013; 62: 286-290

44) Ohman EM, Roe MT, Steg PG, James SK, Povsic TJ, White J, Rockhold F, Plotnikov A, Mundl H, Strony J, Sun X, Husted S, Tendera M, Montalescot G, Bahit MC, Ardissino D, Bueno H, Claeys MJ, Nicolau JC, Cornel JH, Goto S, Kiss RG, Güray Ü, Park D-W, Bode C, Welsh RC, Gibson CM: Clinically significant bleeding with low-dose rivaroxaban versus aspirin, in addition to P2Y12 inhibition, in acute coronary syndromes (GEMINI-ACS-1): a double-blind, multicentre, randomised trial. Lancet, 2017; 389: 1799-1808

45) Eikelboom JW, Connolly SJ, Bosch J, Dagenais GR, Hart RG, Shestakovska O, Diaz R, Alings M, Lonn EM, Anand SS, Widimsky P, Hori M, Avezum A, Piegas LS, Branch KRH, Probstfield J, Bhatt DL, Zhu J, Liang Y,
Maggioni AP, Lopez-Jaramillo P, O’Donnell M, Kakkar AK, Fox KAA, Parkhomenko AN, Ertl G, Störk S, Keltai M, Ryden L, Pogosova N, Dans AL, Lanas F, Commerford PJ, Torp-Pedersen C, Guzik TJ, Verhamme PB, Vinereanu D, Kim J-H, Tonkin AM, Lewis BS, Felix C, Yusoff K, Steg PG, Metsarinne KP, Cook Bruns N, Misselwitz F, Chen E, Leong D, Yusuf S, COMPASS Investigators: Rivaroxaban with or without aspirin in stable cardiovascular disease. N Engl J Med, 2017; 377: 1319-1330

46) Gurbel PA, Tantry US: GEMINI-ACS-1: toward unearthing the antithrombotic therapy cornerstone for acute coronary syndromes. Lancet, 2017; 389: 1773-1775

47) Yasuda S, Kaikita K, Akao M, Ako J, Matoba T, Nakamura M, Miyauchi K, Hagiwara N, Kimura K, Hirayama A, Matsui K, Ogawa H, AFIRE Investigators: Antithrombotic therapy for atrial fibrillation with stable coronary disease. N Engl J Med, 2019; 381: 1103-1113

48) Chaabane C, Otsuka F, Virmani R, Bochaton-Piallat ML: Biological responses in stented arteries. Cardiovasc Res, 2013; 99: 353-363 